Archivum, LXXI, 2021, pp. 213-243

\title{
Asuntos dominantes en el trabajo periodístico de Rafael Chirbes a partir de los textos de la revista Ozono (1975 y 1979)
}

\author{
JACOBo Llamas Martínez \\ UNIVERSIDAD DE LEÓN \\ jllam@unileon.es
}

Recibido: 02/09/2020

Aceptado: 03/10/2021

\section{RESUMEN:}

En este trabajo se revisa la labor como periodista de Rafael Chirbes, con especial atención a sus textos firmados en Ozono, "revista de música y otras muchas cosas", de la que fue miembro fundador y colaborador habitual desde la creación a mediados de 1975 hasta la desaparición a finales de 1979. El análisis de los reportajes, entrevistas, artículos y reseñas que publicó revela gran parte de las virtudes que se le reconocieron con posterioridad como novelista - rigor, independencia, erudición, estilo propio-, y aporta claves biográficas, ideológicas y literarias para un mejor conocimiento de su trayectoria y obra. Con este artículo se evidencia, además, la necesidad de seguir recuperando textos, documentos y testigos del pasado para ponderar con ecuanimidad la historia española reciente.

PALABRAS CLAVE: Rafael Chirbes, periodista, reportero, Ozono, biografia, Transición. 


\title{
Rafael Chirbes's journalistic work and his texts for Ozono magazine between 1975 and 1979
}

\begin{abstract}
:
This article reviews Rafael Chirbes's work as a journalist, with particular attention to the texts he authored in Ozono, a "music magazine and many other things", of which he was a founding member and regular collaborator from its creation in mid-1975 until its disappearance at the end of 1979. The analysis of the reports, interviews, articles and reviews that Chirbes published reveals many of the virtues that were later attributed to him as a novelist - rigour, independence, erudition, his own style-, and provides biographical, ideological and literary keys to understanding his career and work. This article also demonstrates the need to continue recovering texts, documents and witnesses from the past in order to evaluate recent Spanish history with equanimity.
\end{abstract}

KEYWORDS: Rafael Chirbes, journalist, reporter, Ozono, biography, Spanish Transition.

La canonización en España de la obra de Rafael Chirbes por la importancia y el número de los premios recibidos, por su maestría y por la buena recepción de sus novelas en países como Alemania, así como su punto de vista y forma de novelar, invita a ampliar el estudio de su figura y producción. ${ }^{1}$ Una de las facetas menos atendidas por el momento de su trayectoria y obra es la periodística, pese al tiempo y a la constancia con que se

1 Chirbes fue galardonado con el Premio de la Crítica Valenciana por La caída de Madrid (2000) y el Premio Cálamo por Los viejos amigos (2003); Crematorio (2007) fue reconocido con ambos premios y con el Premio de la Crítica de Narrativa Castellana y el Dulce Chacón; En la orilla (2013) repitió los premios de la Crítica narrativa castellana y el de la Crítica valenciana, y obtuvo el Premio Francisco Umbral y el Premio ICON al Pensamiento (a la difusión de la obra de Chirbes en España también contribuyó la adaptación de Crematorio como serie de televisión en 2011). El novelista gozó de un reconocimiento temprano en Alemania merced al crítico Marcel Reich-Ranicki, quien destacó los valores literarios y éticos de La buena letra (1992) y La larga marcha (1996), ganadora en 1999 del Premio SWR-Bestenliste (más datos en Aniorte, 2012, y Herralde, 2006). Alfons Cervera, Marta Sanz, Isaac Rosa, Santos Alonso, Santos Sanz Villanueva, Manuel Rodríguez Rivero, Ángel Basanta o Fernando Valls son los escritores, profesores y críticos que reivindican la obra de Chirbes con más pujanza. 
dedicó a ello entre 1975 y 2007, y a que en estos textos periodísticos ensayó y avanzó buena parte de las virtudes que se le reconocieron posteriormente como novelista: criterio propio, osadía, rigor ético y moral o exigencia estilística. Para conocer mejor esta labor, en este trabajo se estudian los textos firmados por Chirbes para la revista Ozono, en los que se descubren claves biográficas e ideológicas, y las primeras evidencias de las fuentes literarias y cinematográficas de su obra más allá de los libros editados antes de la primavera de 1975 que se custodian en la Fundació Rafael Chirbes (sobre esta última cuestión véase Llamas, 2020).

\section{Chirbes periodista}

Antes de darse a conocer como novelista con Mimoun (1988), Chirbes ejerció de librero, profesor y reportero. Su actividad más conocida y duradera como periodista lo ligó a la revista Sobremesa desde el primer número de febrero de 1984 hasta 2007, en la que se desempeñó como redactor, redactor jefe, director, asesor de dirección y colaborador, y para la que escribió numerosos artículos y reportajes gastronómicos y de viajes. Chirbes condensó parte de esta labor en los doce reportajes de viajes compilados en Mediterráneos (1997) y en los cuarenta y dos en El viajero sedentario (2004), sin embargo, otros reportajes, entrevistas y artículos publicados por Chirbes en Sobremesa merecerían una mayor divulgación por sus observaciones y por su contenido y estilo. ${ }^{2} \mathrm{La}$

2 De los estudios que conozco sobre los reportajes de Chirbes, Veiga (2011), García Prats (2013), Martínez Rubio (2016), Burgos Segarra (2021) y Fernández Martínez (2021), solo Burgos Segarra cita algunos no compilados en Mediterráneos y El viajero sedentario. El cambio de formato supuso la supresión de despieces, fotos, pies de foto, ladillos, e implicó, como reconoció el propio Chirbes (1997, 167, y 2004, 371), modificaciones de distinta índole que confirman el rigor con el que escribió y revisó sus textos. De acuerdo con Val (2014-2015, 288), en 1982 Chirbes "llega a Madrid y pasa algún tiempo en La Gaceta Ilustrada", antes de iniciar su relación con Vinoselección, el club de vinos para el que creó la revista Sobremesa con el objetivo garantizarse un trabajo y un sueldo. Con todo, Chirbes ya tenía la ambición de ser escritor tal como demostró en 1981 con la presentación al Premio Sésamo de Las fronteras de África, novela inédita y hoy perdida, y como explicitó en sus diarios inéditos, A ratos perdidos, disponibles para la consulta en la Fundació Rafael Chirbes 
severa lectura sociológica que ofreció en ellos de diversos aspectos históricos, geográficos, económicos, gastronómicos, prueban la fascinación de Chirbes por los oficios humildes, el esfuerzo y el trabajo bien hechos, y el lamento - ya desde mediados de los años ochenta - por la pérdida de tradiciones ante el empuje del capitalismo, el turismo y la globalización, que priman la rentabilidad, la sofisticación y lo reconocible y homogéneo de cada país en detrimento del cooperativismo y de las especificidades paisajísticas, orográficas, productivas y culinarias de cada región o territorio. El novelista censuró de paso aquellas leyes beneficiosas para el comercio y la especulación y contrarias a la singularidad, y las recomendaciones y medidas de salud pública que atentaban contra la libertad de un fumador y bebedor como él y contra los intereses de Sobremesa, una revista culinaria promovida y financiada por restauradores, viticultores y bodegueros. Ejemplos de todo ello son los reportajes "De Mariola al mar" (Chirbes, 1984), “Las trufas. En busca del diamante negro" (Chirbes, 1985), “Ostras en el Atlántico francés. El jardín sumergido" (Chirbes, 1987a) o "Champagne. El lujo como equilibrio" (Chirbes, 1988).

En todos estos reportajes, propios del periodismo cultural aunque con mucho mayor peso de la conciencia de clase, destaca además la precisión del vocabulario de Chirbes que, como el caso de Ignacio Aldecoa en Gran Sol (véase Chirbes, 2010: 162168), sirve para honrar los oficios tradicionales al nombrar con exquisito rigor actividades y aperos, y constituye una muestra más de perspicacia y de los riesgos del colonialismo cultural y lingüístico. En consecuencia, el estilo de estos reportajes refuerza los aspectos colonizadores, humildes y de clase que menudean en las novelas de Chirbes:

y en cuya primera entrada de abril de 1984 constató: "Así, ¿cómo escribir, si todo está en suspenso, a la espera de alguna forma de normalidad?" (Chirbes, 2001, 63). El abandono de Sobremesa obedeció a desavenencias del escritor con los responsables de la publicación, que potenciaban artículos más propios de la moda y el comercio que de la cultura, y a su deseo de centrarse en la literatura tras el éxito de Crematorio. 
Con un cuchillo de hoja triangular, parecido a una paleta de albañil, cava cuidadosamente en círculo hasta dejar suelto el hongo. (Chirbes, 1985, 21)

Y es que, si Bali no es el paraíso, es la caverna platónica que permite ver sus sombras de verdad y belleza, y permite, sobre todo, reflexionar acerca de todas las sabidurías aplastadas por la sabiduría occidental. (Chirbes, 1990a, 66)

En estos textos firmados en Sobremesa, Chirbes explotó otro recurso habitual de ciertos pasajes de sus novelas, la continuidad semántica de los referentes lingüísticos ("ensalada", "verde", "lechuga"; "oso", "lince", "zorro", "lobo"...; "nieve", "pureza", "desierto"), y la alternancia de períodos sintácticos breves y extensos con una motivación rítmica y semántica (en el caso citado abajo, las intermitencias de la lluvia parisina): ${ }^{3}$

Pasó frente a la terraza un pintor con traje y corbata que se volvió - antes de torcer para mirarle las piernas a una austríaca que se estaba comiendo una ensalada. La austríaca ni se enteró. Tenía la mirada perdida entre las venas verdes de una hoja de lechuga. (Chirbes, 1987c, 62)

La nieve no era un sudario, sino un manto que ocultaba la vida. Estábamos en la patria del reno, pero también del oso, del lince, del zorro, el lobo y el glotón de la nutria, el armiño y la marta. El aire era de una pureza aterradora en aquel lugar desierto, en el que cuatro huellas de hombre venían a añadirse a las de la liebre, el ave y el zorro. Del mismo modo que el Sahara bulle de vida, así también son un falso desierto los parajes árticos. (Chirbes, 1989, 60-62)

Había llovido, había dejado de llover y ahora caída de nuevo esa elegante lluvia de París, que levanta las solapas de las gabar- 
dinas de firma y pone a bailar una nube de paraguas made in Italy. Llevaba así tres o cuatro días. De vez en cuando, como si quisieran tomarse un respiro, se acurrucaban en torno a la ciudad y tapaban la punta de la Torre Eiffel. Entonces llovía, durante un parte de horas, hasta que, de repente, salía no se sabe de dónde el sol y ponía a arder las hojas de los plátanos del boulevard Saint Germain, doradas ya por el otoño; y encendía los castaños de las orillas del Sena, de color verde y cobre. Y luego, vuelta al agua, a la exquisita lluvia de París. (Chirbes, 1990b, 22)

También son muy destacadas las entrevistas realizadas por Chirbes en Sobremesa a cocineros, hosteleros y bodegueros, en las que arremetió contra los nuevos hábitos y gustos de las clases acomodadas españolas de los años ochenta, que fueron las que renunciaron a los ideales revolucionarios de justicia e igualdad y para las que precisamente se creó la revista. A pesar de la motivación propagandística de estos textos, de la crítica no se libraron ni los entrevistados, a los que el escritor responsabilizó de las recientes y lujosas costumbres. Las alusiones a los chefs estrella de la nouvelle cuisine en una entrevista a Juan María Arzak es uno de los casos más significativos:

[Arzak] ha conseguido convertirse en la estrella indiscutida de la cocina; en su gran vedette [...] De él hablan bien incluso quienes no han comido jamás allí [...] Sabe estar atento a todos los humos de los fogones europeos, e incorporarlos antes que nadie de aquí. Su restaurante ofrece algo más que cocina: expende el certificado de garantía del gusto de una nueva capa social.

$[\ldots]$

España se desperezaba del sueño letal de los cuarenta años. Lo vasco estaba de moda. Eran los tiempos en que los progres de Madrid aún llamaban Aitor al primer nacido varón y Ainhoa a la que cerraba la parejita [...]. Un buen segmento de los españoles estaba aprendiendo, además de a votar, a comer. Los estudiantes de Burgos y del 68, concluidos felizmente sus estudios, empezaban a 
encontrar sus primeros empleos bien remunerados y estaban como perdidos ante las mesas. En su educación sentimental no había entrado la gastronomía; y el norte, además de otras cosas, les regaló sus profesores del estómago. (Chirbes, 1987b, 32 y 36) ${ }^{4}$

A medida que se fue consolidando como novelista desde mediados de los años noventa, Chirbes dejó de realizar entrevistas y de participar en degustaciones de corte promocional, y se centró en los reportajes de viajes, que en su última etapa en la revista se volvieron una obligación resuelta con más oficio que talento y se basaron más en la bibliografía que en la observación como reconoció en una entrada de sus diarios del 9 de junio de 2006: "[...] en los reportajes que escribo sobre las ciudades que visito, la bibliografía ocupa cada vez más el lugar que debería ocupar la observación, la experiencia del reportero" (Chirbes, A ratos perdidos, 4, 130).

El trabajo de Chirbes en Sobremesa le permitió tratar también con personas decisivas en su desempeño como novelista, como Carmen Martín Gaite, a la que entrevistó para el número 98 de la revista (Chirbes, 1992), o Vázquez Montalbán, asiduo colaborador de Sobremesa, con quien compartió presentaciones y a quien dedicó artículos y hasta lo que parece un relato inédito en posesión de Alejandro Nogales, La otra mitad, rubricado en octubre de 1994 en Valverde de Burguillos (Badajoz). ${ }^{5}$

Pero la trayectoria periodística de Chirbes es mucho más dilatada. Val $(2014-2015,287)$ resume su paso por la revista Ozono y da cuenta de sus colaboraciones en las revistas Reseña, Cuadernos para el diálogo y La Calle durante los años setenta. A su vuelta

4 Los personajes de En la lucha final (1991) y Los viejos amigos responden a esta sibilina caracterización. A Arzak se volvió a referir significativamente Chirbes en En la orilla (2013): "aún no eran exactamente estrellas los cocineros, fue en la fase previa, cuando, como dijo Arzak, los chefs empezaban a tener la misma consideración que un ingeniero, un arquitecto un médico [...]" (Chirbes, 2016, 211).

5 Alejandro Nogales Hernández conoció y se hizo amigo de Rafael Chirbes alrededor del año 1988, poco después de que este se instalase en Valverde de Burguillos, donde vivió hasta el año 2000. 
de Marruecos en 1981, y nuevamente según Val (2014-2015, 288), Chirbes obtuvo un trabajo "como redactor de mesa en el Grupo Zeta, primero en Madrid y, luego, en Barcelona", donde elabora "artículos de prensa del corazón", ocupación que dejó en cuanto consiguió un puesto en el Ideal Gallego de A Coruña. En octubre de 1982 renunció al trabajo por disensiones con el director del periódico que deseaba llevar a la portada un titular sobre Manuel Fraga, "el líder que más ha crecido en voto", y obviar el holgado triunfo de Felipe González en las elecciones generales del 28 de octubre de 1982. ${ }^{6}$ Fue entonces cuando Chirbes volvió a Madrid para formar parte de La Gaceta Ilustrada, paso previo a la fundación de Sobremesa en 1984 (véase Val, 2014-2015, 288). A partir de 1985, y hasta poco antes de su muerte en 2015, publicó una columna en Hoja del mar y desde finales de 2004 en la revista Descobrir. Tras la publicación de La caída de Madrid (2000), firmó textos esporádicamente en El País, Babelia, El Cultural, Livres Hebdo o el Anuario de la Cocina de la Comunitat Valenciana. ${ }^{7}$ Como sucede con los artículos y reportajes de Sobremesa, los publicados en el Anuario abundan, gracias a su corrosivo estilo, en la despiadada visión de la naturaleza humana:

Pucheros, ollas y escudellas nos hablan del orgullo del animal humano culturizado, que no se conforma con arrojar un pedazo de carne sobre las llamas: el cocinero de pucheros y ollas se supone que maneja la alfarería, ha estabulado a los animales y cultiva sus propias verduras. Además, qué duda cabe, los pucheros y las ollas son el inicio de la verdadera cocina, la madre de todos los recetarios.

\section{$[\ldots]$}

Pero no hay que olvidarse de que los valencianos contamos con el más glorioso puchero de corte postarábigo, porque ¿qué otra

6 No se han podido documentar textos firmados por Chirbes en El Ideal Gallego en 1981 ni en 1982, quizá porque el trabajo como redactor le limitó a identificarse como "Redacción".

7 Uno de los de Babelia y dos de los de Livres Hebdo figuran en Chirbes (2010a, 206-218). 
cosa son todos esos arroces caldosos, más que pucheros u olletes reconvertidos después de que los moros introdujeran en nuestras tierras el arroz? (Chirbes, 2008, 206 y 208)

En este trabajo se revisa, sin embargo, el período de lo que podría denominarse el primer Chirbes, es decir, el Chirbes que a punto de cumplir veintiséis años se curtió publicando sus primeros textos en revistas como Ozono, de la que fue miembro fundador y en la que participó puntualmente demostrando el deseo de ganarse la vida escribiendo y el afán de intervenir en los asuntos culturales, sociales y de gobierno para dar continuidad a la militancia de sus años universitarios. A principios de los ochenta se desentendería del debate público por discrepancias ideológicas con los militantes del Partido Comunista de España que renunciaron a los ideales revolucionarios y buscaron una oportunidad política incorporándose al Partido Socialista Obrero Español. ${ }^{8}$ Estos primeros textos conocidos de Chirbes exhiben el bagaje ideológico, artístico y cultural a partir del que fraguó sus convicciones y escribió su obra, y apuntan amistades y contactos con intelectuales y escritores de su generación y de otras anteriores.

A continuación se destacan los asuntos dominantes: el rechazo de los fundamentos del proceso de transición democrático en España; el realismo literario entendido como una forma de interpretar la realidad complementaria a la historia; el discurso de clase; y la crítica de la cultura de consumo, que convierte a los creadores en vedetes, a productores y editores en tratantes, y las

8 Desencantado con la situación política española, el curso 1979-1980 Chirbes dio clases en la Universidad de Fez; a su regreso a España se encontró con un ambiente político y social que no le agradó y que una entrada en sus diarios del 24 de mayo de 1984 ilustró: "Acaban de pasar por la calle de Toledo miles de manifestantes de Comisiones Obreras. No sé qué reclaman. Desde aquí no podía entender sus voces, ni leer sus pancartas. Qué tiempos aquellos en los que cualquier reivindicación era asunto tuyo. Ahora, eso se lo han quedado en exclusiva los profesionales del tema. Tuvo que llegar la democracia para que nos sintiéramos expulsados de la política" (Chirbes, 2021, 116). 
obras editoriales y cinematográficas en productos de mercado en vez de en fuentes de conocimiento, reflexión y deleite. Todas estas constantes, que se pueden desarrollar en detalle en sucesivos trabajos, contribuyen a historiar con mayor propiedad la obra de Chirbes, y a mejorar la interpretación del conjunto de su producción, necesitada de análisis alejados de clichés, partidismos, rivalidades o escuelas y metodologías que desvirtúan la esencia de su escritura y persona.

\section{Constantes dominantes en los textos de Chirbes en Ozono}

De acuerdo con Val (2014-2015, 286), Chirbes fue miembro del consejo asesor de la revista Ozono "desde el número cero [el número uno es de mayo de 1975] al final, tirado en 1979, cuando ya estaba mandando sus colaboraciones desde Marruecos". La publicación, una especie de fanzine que se definía desde su cabecera como una "revista de música y otras muchas cosas", tuvo poca repercusión por la escasa autoridad de sus jóvenes colaboradores en aquel tiempo, aunque algunos como Ramón Chao, Ignacio Ramonet, su director, Álvaro Feito, Manu Leguineche, Cesar Antonio Molina, Juan de Pablos o Diego A. Manrique serían en la década siguiente periodistas y figuras reconocidas cultural y políticamente. Chirbes, que no gozó de un reconocimiento semejante hasta finales de los noventa, coordinó la sección "Guía de libros" en la que firmó numerosas reseñas sobre obras literarias, políticas, filosóficas, pero también publicó críticas cinematográficas - la segunda de sus devociones tras la literaria-, reportajes, entrevistas y artículos de opinión en otras secciones de la revista. ${ }^{9}$

9 Chirbes evocó muy de pasada en sus diarios la etapa en Ozono y a uno de sus compañeros, Francisco Fernández Buey: "Veo Alta fidelidad, de Stephen Frears: la música, la vinilomanía y todas esas cosas: mundo contemporáneo (tuve muchos compañeros así, con esas pasiones, yo mismo escribí en Ozono, una revista hecha por y para gente de esos mundos musicales) que se me ha escapado y al que ya no voy a tener acceso [...]"; "Charla en la Pompeu Fabra de Barcelona. Grato encuentro con Fernández Buey. Descubrimos que, sin conocernos, hemos estado en contacto hace muchos años a través de la revista Ozono, en la que ambos colaboramos. Eso fue en la segunda mitad de los setenta" (Chirbes A ratos perdidos, 5, 158; 4, 191). La 
Desconozco el número exacto de textos que firmó, porque no he podido consultar los cincuenta números de Ozono existentes dadas las limitaciones actuales. Con todo, los veintiuno examinados avanzan varias conclusiones para nuevas y significativas vías de investigación. Por tanto, y sin pontificar o generalizar en exceso, el interés de los textos de Chirbes en Ozono radica en la visión coyuntural del momento en el que fueron escritos y en su postura personal frente a ciertos libros y autores y a ciertos hechos y decisiones políticas. En todos ellos se percibe asimismo el afán del autor por fundamentar sus juicios narratológicos en criterios sociológicos en boga en la época, y la independencia de sus convencimientos como la "crítica apasionada - en palabras de Val (20142015, 286) - de la primera parte de Antagonía" de Luis Goytisolo.

\subsection{La censura de los fundamentos del proceso democrático}

En el ámbito propiamente político destaca el artículo "Tomar una papeleta al azar con amargura", al que se puede añadir por las afinidades argumentales y temáticas el titulado "El País. La discreta tendenciosidad del centro". Chirbes denunció en ambos el consenso estratégico entre líderes políticos y poderes fácticos para la legitimación de la reciente democracia española con el tono acre y beligerante que le distinguió, y que fue frecuente también en publicaciones "contraculturales" como Ozono, que se hacían eco del sentimiento de organizaciones de izquierda menos institucionalizadas o sin institucionalizar: ${ }^{10}$

Cuando agoniza el carisma de la porra amanece el día del consenso. Quienes tienen el poder necesitan ese día, como el aire, borrar sus orígenes: los orígenes del poder siempre son turbios y dejan un olor pegajoso. [Punto y aparte] Para mantener su dominio inician un "doy para que me des", intentando perder en este cam-

primera de las citas evidencia, además, que Chirbes fue mucho más cinéfilo que melómano.

10 En esta misma línea se situaron cabeceras mejor estudiadas y de mayor duración y repercusión que Ozono como Star, Nueva Lente y Ajoblanco. 
bio lo menos posible. Ofrecen dejar dormir la verga a cambio de que la inmensa mayoría aceptemos como universales y eternas las reglas de un juego que acaban de inventarse. (Chirbes, 1977e, 41)

Esto, sin duda, va viento en popa: uniendo a los partidos, el Pacto de la Moncloa; por encima, el Mayúsculo Innombrable; y más arriba, en la nevada cumbre, El País, rozando la síntesis hegeliana o la unidad de destino en lo universal, que diría Carlos Marx [...] ¿Cómo es posible - se preguntará atónito el lector- que en pocos meses haya surgido de la noche oscura del alma franquista un equipo tan esmeradamente preparado para el relevo? ¿Casualidad, providencia, azar o necesidad? Nada de eso: no ha sido obra de un día, ni siquiera de meses. Se trata de una tarea de años a la espera del momento [...]. Años de contactar, devorar, potenciar y penetrar -sí, también penetrar- [...]. (Chirbes, 1977h, 36)

Chirbes (1977e, 40) desglosó la premisa de que la democracia española fue un acuerdo partidista entre distintas élites económicas y políticas del que se beneficiaron aquellos que lo orquestaron y perpetuaron; el resto fueron ninguneados y apartados de las esferas de decisión y poder. En la transición de la dictadura a la democracia las instituciones franquistas cedieron lo imprescindible y los "partidos obreros y populares" se plegaron al arbitrio de "tribunales que [...] condenaban a cárcel [...] a cuantos luchaban" por la libertad "tras un bochornoso espectáculo de "sálvese quien pueda", desunión y renuncias". ${ }^{11}$ Los que pactaron la celebración de las elecciones de 1977 renegaron de las aspiraciones revolucionarias, fomentaron valores burgueses y aceptaron que la Ley D'Hont restase representatividad a las ciudades, "eternas portadoras de repúblicas y revoluciones sociales", para asegurar - siempre según Chirbes - la derrota de los partidos de izquierdas. Por ello, y aunque inútil políticamente, la

11 Chirbes censuró con ello a los líderes del Partido Comunista Español que aceptaron presentarse a las elecciones de 1977 pese a que otras organizaciones minoritarias y afines seguían ilegalizadas. 
abstención en las elecciones generales españolas del 15 de junio de 1977 era la única opción ética para el novelista, quien cerró el artículo con sorna: "Quizá, lo más sencillo, sea fabricar una serie de papeletas con las siglas de los partidos obreros y tomar una al azar con amargura" (Chirbes, 1977e, 41).

Consumada la victoria parlamentaria de la coalición Unión de Centro Democrática, el gobierno de Adolfo Suárez asumió la subrogación de los ideales sociales y revolucionarios para propugnar la moderación del centro como síntoma de democracia y progreso al modo norteamericano y de la Comunidad Económica Europea que El País se arrogó y se avino a difundir según Chirbes (1977h). Pero este supuesto centrismo representado por Suárez, que se proclamó equidistante ideológicamente, amparó el relativismo ético y moral y la impunidad de las nuevas instituciones y de sus miembros. De este modo, cualquier intento de cuestionar sus resoluciones y a sus representantes estaba fuera de lugar por tendenciosa o partidaria, y porque supondría oponerse a los ideales democráticos que ostentaban en tanto que representantes del pueblo:

Por encima de opciones políticas, importa el equilibrio. Ni a favor ni en contra de nada [...]. Imaginemos que los progres lectores de El País llegásemos a enterarnos de que los pañales de un senador (ojo, no de un político) no fueron democráticos. Sería la desestabilización, que es lo que pretenden comunistas y fascistas (los extremos se tocan). Los senadores deben mantener su imagen. Están bautizados a dedo, mean agua democrática y si mueren van al cielo sin pasar por el purgatorio [...]. A veces pienso que esto de estabilizar significa centrar, pero me lo callo por si acaso. (Chirbes, 1977h, 37) ${ }^{12}$

12 Como recuerda Chirbes $(1977 \mathrm{~h}, 37)$, el fundador de El País, José Ortega Spottorno, fue senador por designación real de la primera legislatura constituyente española (1977-1979): “Sereno es (no de profesión, por supuesto) el presidente del consejo de El País, señor Ortega Spo[t]torno, y así lo ha reconocido el propio Dedo Regio asignándole un sillón en el Senado -institución serena, surgida del sereno consensus de un pueblo sereno". 
Para Chirbes (1977e, 40) el término "centrar" se aproximaba a ideales y valores más propios de la derecha política que a un equidistante punto medio: "El poder se llama derecha o centro y es sólo derecha". Este rotundo rechazo de Chirbes hacia las bases del proceso democrático y preconstitucional fue acompañado en ambos artículos de un tono burdo con el que remedó el estilo de quienes dirigieron el proceso y ridiculizó sus toscos argumentos e impostadas decisiones. La metáfora futbolística y su connotación sexual ("no están dispuestos a admitir goles", Chirbes, 1977e, 41) no dejan lugar a dudas de la disidencia y malestar de Chirbes con los fundamentos de la transición democrática española, ni de la altura intelectual y ética que asignó a quienes lo gobernaron y a sus determinaciones. Ello muestra, además, otra de las cuestiones que más concernieron al novelista, la del lenguaje como representación de realidades diversas (encubridoras o reveladoras) en función de la connotación o el sentido dado a las palabras:

¡Pobre libertad con las braguitas sucias en la noche de bodas [alude a la "noche" del recuento electoral] y difícil partido el que nos van a hacer jugar! [Punto y aparte] Ellos, sin portería: no están acostumbrados a admitir goles. Nuestra portería, como siempre, grande y generosa para que - como siempre- nos los metan todos. (Chirbes, 1977, 40-41)

Las nociones previas fundaron las tesis de Chirbes sobre la democracia y gobiernos españoles desde los años ochenta hasta su muerte acusando al Partido Socialista Obrero Español de traicionar los ideales obreros y sociales para perpetuarse en el gobierno desde 1982, y de reivindicar justicia por los atropellos del franquismo únicamente con fines electoralistas después de la derrota en las elecciones generales de 1996 frente al Partido Popular, deudores axiológicos - también de acuerdo con el novelista - de la Falange Española de las JONS y el desarrollismo franquista. Con todo, fue la hipocresía y cinismo que Chirbes 
atribuyó a dirigentes socialdemócratas como Felipe González, Alfonso Guerra o José Luis Rodríguez Zapatero lo que más excitó sus ánimos. La buena letra, Los disparos del cazador, La caída de Madrid, Los viejos amigos y Crematorio proyectan estas ideas, reconocidas por el novelista en sus diarios, artículos, entrevistas, prólogos y epílogos, y apuntados meridianamente en los dos artículos de Ozono señalados. ${ }^{13}$

En 1977 se cifra, por tanto, la desazón de Chirbes por la deriva del proceso democrático en España en términos muy parecidos a los que sostuvo el resto de su vida. Sus juicios no fueron privativos, pero sí firmes, y cuando parte de ellos se debatieron parcialmente en el parlamento y se plasmaron en leyes como la

13 Aunque se podrían extractar bastantes más, sirvan los fragmentos siguientes de ejemplo: "Igual que ocurrió en los cuarenta, en los febriles ochenta se suponía que el poder cambiaba de manos, y los recién llegados se aprestaban a ocuparlo y descubrían la dulzura del mando y sentían caer sobre sí la gratificante lluvia de las contratas del Estado. España es el país en que se puede ganar más dinero en menos tiempo, proclamaba el altivo ministro de economía [Carlos Solchaga]. [...] El pacto [democrático] que se les propuso a los españoles, bajo el razonable argumento de cambiar pasado por futuro, fue un cambio de ideología por bienestar; es decir, un trueque de verdad por dinero. Y el país lo aceptó. [Punto y aparte] De hecho, quienes proponían esa transacción eran jóvenes que exhibían sus credenciales antifranquistas, reales o contrahechas" (Chirbes, 2013, 7-8). "Zapatero y su ministra de economía han podido presumir ante la oposición de paz social en esa línea postmarxista de que la socialdemocracia es la mejor gestora del capitalismo, y que, por lo demás, cuenta con tan buena tradición en España: en los ochenta fue el gobierno del socialdemócrata Felipe González el encargado de llevar adelante la durísima reconversión industrial que solicitaba el implacable capitalismo europeo; de multiplicar los despidos empresariales hasta elevar el paro a tasas antes nunca imaginadas, de domesticar a varazos a los sindicatos, y de meter al país en la OTAN" (Chirbes, 2010b). A propósito de La buena letra y Los disparos del cazador, Chirbes (2010a, 32-33) comentó: “En ambas novelas, las voces de los viejos actores hacían sonar el lenguaje de sus hijos, los recién llegados al poder [...]; [estos] descubrían el fondo de doblez sobre el que se estaba construyendo esa nueva sociedad, la que treinta años más tarde ha estallado en una gran burbuja de cemento y codicia, oscura propiedad y responsabilidad de nadie". Moreno-Caballud (2012, 541-542) conecta esta visión de Chirbes con algunas propuestas de Rafael Sánchez Ferlosio. Calvo Carilla (2013) estudia el relato de la Transición en La larga marcha (1996), La caída de Madrid, Los viejos amigos y Crematorio. Serber (2019) interpreta Mimoun en esta misma clave política. 
52/2007, de 26 de diciembre, por la que se reconocen y amplían derechos y se establecen medidas a favor de quienes padecieron persecución o violencia durante la guerra civil y la dictadura, Chirbes lo consideró oportunista, hecho a destiempo y nada reparador para familias a las que la guerra y la dictadura desposeyó de lo que poco que tenían. ${ }^{14}$ Esto marcaría definitivamente su desolada y nihilista visión de la sociedad y el hombre, que bordeó lo reaccionario como García Montero subrayó en un artículo sobre En la orilla (2013):

La realidad es una enfermedad mortal, una vejez sin piedad, un pantano, un vertedero. ¿Y ahora qué? Es el momento de preguntarse si esta radicalidad de la mirada negativa mantiene su lealtad a la lucidez o paga la factura del rencor. ¿Es que no hay nada bueno en la vida? ¿Todo ser humano es sospechoso? ¿El amor resulta siempre una estafa? El buenismo, desde luego, falsea cualquier meditación. Pero, en el otro extremo, conviene también preguntarse por el nihilismo totalitario y su voluntad absoluta de descrédito. ¿Sirven para entender la realidad? ¿No son una forma más de acomodarse a los dictados de un poder que pretende cegar cualquier alternativa? La última novela de Rafael Chirbes [En la orilla] me ha dejado estas preocupaciones. (García Montero, 2013) ${ }^{15}$

14 Chirbes expuso su parecer al respecto en cinco artículos publicados entre 2003 y 2009; en Chirbes (2010a, 213-270) los recuperó y agrupó en un significativo epígrafe: "III. Memorias y maniobras". Alfons Cervera, un escritor afín a Chirbes en lo que a la impugnación de la versión institucional dada sobre el pasado español reciente se refiere, considera que - para no dar lugar a malentendidos, puesto que existen dos memorias en lid, la de los franquistas triunfadores y las de los desamparados y represaliados por ese régimen - debería denominarse «Ley de Memoria Democrática y Antifascista».

15 Chirbes (A ratos perdidos, 6, 385) recordó este texto de Luis García Montero al reflexionar sobre Los días terrenales de José Revueltas cuyo "libro fue condenado por el PC mexicano, acusado de pesimismo y de formar parte de lo peor de la ideología burguesa: existencialista. Pienso en el texto que Luis García Montero dedicó a En la orilla, en el que el pesimismo es el gran pecado porque te pone a trabajar a favor del poder". 


\subsection{El realismo como fuente de conocimiento e interpreta- ción de la realidad}

La disidencia de Chirbes se trasladó al resto de sus artículos, reportajes, entrevistas y reseñas de Ozono, aunque en ellos refinó los argumentos y el tono del discurso con respecto a los dos comentados, y evidenció la dependencia de los supuestos sociológicos de los años sesenta y setenta al juzgar la obra de otros autores. (Estas mismas nociones guiaron años después la escritura y la valoración de su propia obra.) Chirbes marcó esta pauta desde el número 1 de Ozono, de mayo de 1975, donde publicó un reportaje dedicado al "método de novelar" de Alejo Carpentier con motivo de la publicación de El recurso del método (1974), y otro sobre adaptaciones literarias en el cine en el que hizo especial hincapié en las de Galdós y en el disgusto que le causó la película Tormento, dirigida por Pedro Olea. En ambos reportajes se revela el temperamento crítico de Chirbes, su voluntad intelectual, que le llevó a introducir aclaraciones a pie de página, y los nexos que advertía entre arte, ideología y política:

[En nota] (1) Es una cuestión complicada la de las implicaciones políticas y sociales de la obra de arte. Al hablar del sustrato común en Borges y Bertolucci me refiero a ese carácter que nos une aún con una obra de arte de la antigüedad clásica, pese a la desaparición de las formas políticas y sociales que condicionaron el nacimiento de la obra y de las cuales la obra es en gran medida un reflejo. (Chirbes, 1975d, 74)

El reportaje sobre Alejo Carpentier adelanta, además, lo más parecido a una teoría de la novela según Chirbes al postular la trascendencia del lenguaje, del perspectivismo y la dialéctica, y de los vínculos sociales e históricos de El siglo de las luces, y al entender el realismo literario de El recurso del método no como un espejo de la realidad, sino como una forma de interpretar unos hechos, de dotarlos de sentido a partir de un orden y de una construcción determinadas. Chirbes transfirió todo ello a sus no- 
velas y volvió a reflexionar sobre estos aspectos conceptuales, formales y de estilo siendo ya un novelista reconocido en artículos y conferencias como las aparecidas en Chirbes (2002 y 2010):

El gusto por la palabra [en El siglo de las luces], enraizado en la precisión conceptual. La riqueza verbal unida a la disciplina que excluye los desenfrenos vacíos. La pasión cultural en el maridaje de la tradición filosófica y literaria de la vieja Europa y el mundo joven americano. [...] La meditación política inherente a cualquier análisis histórico llevado hasta sus últimas consecuencias. El amor a la cultura manifestado en su saber enciclopédico.

$[\ldots]$

Carpentier [en El recurso del método] supera un realismo estrecho introduciendo una amplia gama de peculiaridades opuestas entre sí. Proclama como métodos expositivo y analítico las reglas de la dialéctica y el juego de oposición de contrarios. [...] Así, la superación del realismo se lleva a cabo sin caer en la trampa de propuestas individualistas, subjetivas e irracionalistas. El alejamiento, la distorsión de la realidad no son sino medios para su mejor comprensión. Lo subjetivo adquiere la plenitud de su significación, integrándose en un marco más amplio. (Chirbes, 1975a, 70 y 71) ${ }^{16}$

\subsection{La cultura de consumo y el discurso de clase}

El resto de reportajes literarios y cinematográficos de Chirbes en Ozono se fundamentan en esos parámetros; demuestran

16 En este primer número de Ozono, Chirbes $(1975 b, 79)$ reseñó la Poesía completa de Cernuda (Barcelona, Barral Editores, 1974). En ella resaltó el oportunismo de las editoriales al recuperar autores y asuntos controvertidos con tardanza y solo por razones económicas; los valores conceptuales de la forma ("la mera forma se convierte así en contenido por encima del discernir conceptual de cada poema"), y la marginación del poeta entre ciertos sectores de la izquierda por su poesía poco comprometida, algo que se generalizó entre una parte de la crítica española a finales de los años setenta y principios de los ochenta al tachar de imperialistas o de complacientes con el liberalismo obras con fines recreativos o evasivos como, verbigracia, los filmes de Woody Allen. La Fundació Rafael Chirbes conserva ocho ejemplares de Cernuda leídos concienzudamente por el novelista, entre ellos el de la reseña citada. 
su erudición y cinefilia; y apuntan su tendencia polémica y a la contra al destacar las virtudes de Furtivos - una película de más agrado para el novelista que Tormento pero peor recibida por la crítica (Chirbes 1975e) - , y lo incómodo de sus opiniones para el establishment cultural español:

El señor Lara es un señor inteligente. El señor Lara es uno de los más inteligentes del país, en lo que a libros se refiere. Regenta una editorial. Esa editorial se llama Planeta, y sabe estar a la altura de los tiempos: sabe qué es lo que hoy ya se puede cuando ayer aún no se podía. (Chirbes, 1975c, 68)

El lector, profesional o aficionado, se pregunta: ¿Caerá Seix Barral en manos del señor Lara (don José Manuel)? [...] El problema es viejo: nació cuando se casaron, en yo no sé qué iglesia, la cultura y las pesetas. Matrimonio que - pese a la crisis de la pareja - sigue, al parecer, viento en popa. (Chirbes, 1976, 31)

Es, por otra parte, evidente que no es el mismo acto el escribir que el publicar: ¿se están escribiendo grandes novelas que no tienen acceso al gran público por un bloqueo editorial [...] La narrativa parece buscar a ciegas cuál puede ser su función en la dinámica de la sociedad [...] Mientras tanto, el vacío pesa como una losa: poco, muy poco de nuevo hay que destacar. Individuos aislados, problemáticas raramente comunes, desgana editorial, traducciones y reediciones de autores consagrados, desconfianza ante todo lo nuevo, una larga carrera de obstáculos, de cribas y censuras... (Chirbes, 1977c, 13)

Manuel Gutiérrez ha sido premiado en el reciente Festival de Berlín como mejor director, por su película Camada negra. Televisión Española, con el alegre desparpajo que caracteriza a todos los organismos oficiales del país, se ha apresurado a entrevistarle varias veces. Lo que hace un oso plateado. No había entrevistas hace unos meses, cuando la película fue prohibida. (Chirbes, 1977f, 47) 
La historia, desde el mero sarcasmo, es la historia desde el amargo punto ninguno. En historia el análisis ha de venir desde condicionantes muy concretos: por ejemplo, de clase. Privado de ellos todo queda como mero decorado sin soporte. [...] También eso podría explicarnos por qué El tambor... [de hojalata] parece, pese a su aparente funcionalidad, tener doscientas páginas de más. (Chirbes, 1978,60$)^{17}$

Delibes [en El disputado voto del señor Cayo] se ha dejado atrapar en la trampa de reproducir un lenguaje falso, vacío y hueco [...]. La plaga, la furiosa plaga del irrealismo de guiño, sigue cobrando sus víctimas, neutralizando lo real una vez más, en un juego de alternancias metafísicas que, aquí, en el último Delibes, cobran toda su evidencia a costa de perder cualquier ápice de grandeza y de pasar, él también, por el largo túnel de lo vulgar. ¡Ah! Y atención al precio de venta al público. (Chirbes, 1979, 49)

Para un desconocido como Chirbes esto no suponía ningún perjuicio y se ajustaba a la crítica cultural de entonces, muy alejada del buenismo actual; el problema fue que adoptó esta actitud como el principal 'capital simbólico' de su escritura y figura, cuyos presupuestos no serían reconocidos unánimemente hasta la aparición de Crematorio. ${ }^{18}$ Estas maneras de Chirbes se repiten en

17 Chirbes (A ratos perdidos, 5, 441) recordó este artículo sobre el Tambor de hojalata de Günter Grass: “Creo que [George Steiner en Lenguaje y silencio] sobrevalora el papel de Grass, que nunca ha sido escritor de mi devoción, aunque es cierto que me interesaron más sus libros primerizos que El tambor de hojalata, libro del que publiqué una crítica muy negativa, creo recordar que en Ozono".

18 En sus diarios Chirbes siguió preciándose de la independencia e incorruptibilidad de sus juicios pese a que ello le granjease cierta ojeriza y pusiese en peligro amistades y contactos. Val (2014-2015, 280-281) explica la fascinación del novelista, compartida con el resto de escritores de su generación, por el cine: "En el colegio de [huérfanos de] León [al que asistió] [...] "Vi muy buen cine, mucho Hitchcock, mucho Ford, Ladislao Vajda, neorrealismo italiano... nos hacían distinguir las panorámicas, los contrapicados, los planos americanos, los fundidos y los encadenados,... Debíamos estar atentos para localizarlos, porque luego nos preguntaban". En la biblioteca, lee libros de la colección Rialp dedicada al cine y, a 
las reseñas más específicas y breves de la "Guía de libros", entre las que destacan el disgusto suscitado por la "fallida" La tía Julia y el escribidor, de Vargas Llosa ("difícilmente puede uno imaginar que se encuentra frente a un texto del autor de Conversación en la catedral", Chirbes, 1977i, 79), y contra En el estado de Juan Benet (las mayúsculas pertenecen al original): "Es el señor Benet, esforzándose en mostrarnos que es culto, irónico. QUE TIENE TANTO INGENIO... y que sabe ESCRIBIR. [...] Y el lector se aburre de tanto narcisismo porque no es listo, ni sutil, ni inteligente ni sabe entender el libro de Benet" (Chirbes, 1977g, 78).

Por el contrario, también hubo una defensa entusiasta y firme de Chirbes de los autores de su interés. Entre ellos figuraron muchos clásicos y escritores ya canonizados en la segunda mitad de los años setenta como Defoe, Stendhal, Melville Kafka, César Vallejo, Steinbeck, Dos Passos, y otros en proceso de canonización a los que apenas se volvió a referir posteriormente como André Malraux, Carson McCullers, Italo Calvino, Julio Cortázar, Manuel Puig, muchos de ellos aún vivos y en activo entonces. A este respecto resultan muy interesantes los juicios sobre las obras de escritores nacidos en la década de los cuarenta que hoy se podrían considerar coetáneos de Chirbes como Lourdes Ortiz, de quien destacó la "rabia" de Luz de la memoria (1976), José María Guelbenzu, de quien alabó El pasajero de ultramar (1976), o José María Merino, quien debutaba con la Novela de Andrés Choz (1976), que Chirbes (1977d, 78) reseñó favorablemente: “Primera novela de alguien que - sin duda - se plantea muy en serio su oficio. [...] Libro lleno de una enorme voluntad de elaboración al que el autor, en algo que me atrevo a calificar como excesiva humildad, ha cortado inexplicablemente $[. . .]^{\prime \prime}$. El resto de juicios de

partir de los doce años, se convierte en comprador habitual de todas las revistas que puede: Nuestro Cine - más tarde se enterará de que era una publicación de tintes ideológicos comunistas -, Film Ideal - más esteticista, era la que más le gustaba-, Cine Estudio - de influencia religiosa - , Fotogramas, y Triunfo, entonces, dedicada al cine [en la Fundació Rafael Chirbes se pueden consultar ejemplares de estas revistas subrayados por el escritor]". 
Chirbes se ajustan a lo esperable, sobre todo al censurar a autores que creyó vinculados al franquismo, sospechosos de estarlo o en contubernio con el poder, como Ramón Tamames, cuya Historia de Elio (1976) es, según Chirbes, una muestra de la pervivencia de lo que Vázquez Montalbán entendió por "franquismo sociológico": ${ }^{19}$

Haciendo un flaco servicio a la clase que dice defender, al partido que pertenece, a los demócratas en general y a Marx y Engels en particular, Tamames ha tergiversado una política de oposición hasta convertirla en siniestra caricatura de la política del propio poder. Y ha demostrado de un modo casi pedagógico cómo la ideología fascista impregna sectores amplios de quienes, de algún modo, se creen rescatados de ella. (Chirbes, 1977a, 65) ${ }^{20}$

19 La lectura de Chirbes de la guerra, la dictadura y la transición democrática españolas se aproximó además a la de traiciones, renuncias y advenedizos narrada por Vázquez Montalbán en novelas como El pianista (1985), con la diferencia de que el sarcasmo y distanciamiento de este se transforma en resentimiento y amargura en Chirbes, para quien esa novela fue la mejor de su autor: "Creo que la última novela de Vázquez Montalbán, El [p]ianista, es la mejor que ha escrito. Sigo leyéndola, aún no la he terminado. Se acerca a lo más alto de Marsé, y toca dolorosamente la traición de la Transición, un capítulo más de la historia como sinónimo de infamia" (Chirbes, 2021, 96). De hecho, la cena de antiguos camaradas universitarios de Los viejos amigos recuerda a la velada de la primera parte, también de antiguos militantes universitarios, de El pianista. Chirbes suscribió asimismo premisas de los personajes como "todos nosotros somos socialdemócratas profundos. Convivimos socialdemócratamente. [...] y tratamos de inculcar en la gente la tesis del mal menor. Es preferible que te suban los impuestos a que te quiten toda posibilidad de ser Rockefeller"; “'Es la revolución, Rosell, la revolución pactada, la filosofía socialdemócrata instaurada, el triunfo de Bernstein sobre Lenin, la Luxemburgo y los fracasados profetas de La Commune'" (Vázquez Montalbán, 1985, 27 y 201). Las numerosas y significativas coincidencias entre Vázquez Montalbán y Chirbes, que demuestran que aquel fue uno de los principales referentes intelectuales o ideológicos de Chirbes en España, merecerían un estudio pormenorizado.

20 Como en casos anteriores, Chirbes se desahogó en el artículo contra la editorial Planeta y su dueño, José Manuel Lara, que "es un hombre listo y sabe bien que no ha comprado la novela, porque por la novela a secas nadie hubiera dado cinco céntimos ni para guión de un tebeo de Florita o Azucena. El señor Lara ha pagado por todas las cosas que hay por detrás de novela y novelista. Por todo eso, quién lo duda, ha pagado bien poco" (Chirbes, 1977a, 65). 
Aunque más anecdótico, un último aspecto destacable en todas estas reseñas de Chirbes es la denuncia del excesivo coste de los libros, con lo que resaltaba la precaria situación económica propia y el lucro de las editoras, una cuestión que la crítica literaria fue dejando de lado, quizá por considerarse de mal gusto, y a la que los libreros han venido achacando una parte de la sempiterna crisis de ventas del libro. ${ }^{21}$

Con sus convicciones bien afianzadas, Chirbes entrevistó para Ozono a escritores como Juan y Luis Goytisolo, la primera firmada a medias con Mauro González Ruano y Alfonso González-Calero. En sus intervenciones no se amilanó; se mostró agudo e incisivo, y reiteró sus intereses sociológicos y narratológicos acerca del realismo literario, de la función de la literatura, de la exigencia de la novela como género, del libro como un producto fugaz y de mercado más... Sirva de ejemplo la apreciación o réplica que introdujo en la entrevista a Luis Goytisolo (reproduzco la letra bastarda del original):

OZONO. - De todos modos creo que se ha recuperado a partir de renuncias. Ha habido una tónica de abandono, que puede parecerme coherente en el caso de tu hermano, en la medida en que viene marcado por un[a] serie de circunstancias - la no menos importante, el exilio - que le han dado una evolución particular, con ese planteamiento suyo de gran traición, pero que es menos comprensible en el resto de la gente que ha continuado escribiendo. Muchos han caído en el silencio. A nivel personal, salvo dos casos de coherencia en una línea de investigación realista. Probablemente haya más que yo no conozco. El primero sería Isaac Montero, cuyos Documentos secretos, en especial el uno, me parecen un intento valioso de replantearse un realismo sin las servidumbres de que hablábamos. El caso parecido sería tu Recuento, que partiendo de las mismas bases no ha basado la fuga formal o estética, sino en la superación de aquellas

21 Los libreros aducen como otro problema el de las ventas directas a entidades que asumen precios que los lectores presumen inflados y abusivos, y la financiación de libros por parte de esas mismas instituciones, que reportan beneficio a las editoras con independencia de su adquisición en librerías. 
premisas, intentando ajustarse a una realidad más compleja, en la que los héroes tienen relativos, los personajes pobres llegan a ser negativos, etc. (Chirbes, 1977b, 60)

En los textos de Ozono aparecen, además, más asuntos clave de la producción y vida de Chirbes, como el suicidio, que rondó su cabeza en varias ocasiones, el consumo de alcohol o la educación católica. Otros escritos periodísticos de Chirbes dignos de estudio y coincidentes cronológica y conceptualmente con los publicados en Ozono son los de las revistas Reseña. De Literatura, Arte y Espectáculos, Cuadernos para el Diálogo y Saida. Quincenario de Información y Crítica, en las que también firmó reseñas, artículos y reportajes como "[L]as novelas del mayo francés" o "[L]iteratura, salvación y condena. [D]esgracia indeseada. Peter Handke", y en las que coincidió con otras personas importantes en su trayectoria literaria, como el mencionado editor y crítico Manuel Rodríguez Rivero y Santos Alonso, colaboradores ambos de Reseña. Con el segundo Chirbes compartió dos sesiones en la Fundación March en 2009, y leyó con ahínco su edición de las Obras completas de Baltasar Gracián (Madrid, Cátedra, 2011).

\section{La labor periodística de Chirbes, un reflejo de su literatura y carácter}

Chirbes cultivó casi todos los géneros periodísticos, la reseña, el artículo el reportaje, la entrevista, cuyos asuntos y juicios denotan inquietudes políticas, éticas y literarias en las que insistió como persona y escritor. Así, lo que empezó siendo una profesión alimenticia y para alejarse de la realidad política y social española que le desagradaba, se acabó convirtiendo en una anticipación de su ideario y literatura. ${ }^{22}$ Los textos que publicó en Ozono entre 1975 y 1979 establecieron su visión sobre la ilegi-

22 Chirbes (2004, 371-372) resumió esta percepción: “[...] hubo un tiempo en el que viajar salvó de sí mismo a un joven que peleaba contra una realidad gris que lo rodeaba, asfixiándolo, y de la cual le costó mucho tiempo darse cuenta de que él también formaba parte". 
timidad de la democracia española actual, orquestada entre los poderes fácticos y las élites franquistas, cuyos objetivos fueron los de mitigar las ansias de libertad, justicia e igualdad de ciertos sectores de la población, y los de evitar la depuración de responsabilidades. Sobre estas bases se creó una democracia imperfecta que a lo largo de los años ochenta dio cobertura legal a la especulación y menoscabó los ideales solidarios y las costumbres, tradiciones y modos de producción autóctonos, tal como censuró en Sobremesa. El resultado fue el de un país dominado por los intereses, lenguajes y tecnologías capitalistas, el comercio, el turismo masivo y los vacuos valores de la modernidad, que favorecieron la explotación y la precariedad. Los 'fastos' de las Olimpiadas de Barcelona y la Exposición Universal de Sevilla representaron para Chirbes el summum de estos valores que condujeron al colapso político, económico y social de 2008, un colapso que una sociedad degradada e inmoral como la española - que desde los años setenta había fomentado el egoísmo y el expolio, y en la que los contactos y el corporativismo contaban tanto o más que el esfuerzo y el talento - no podía enmendar. Los denuestos de Chirbes contra los sucesivos gobiernos e instituciones españolas recientes - contrarios, en su opinión, a los valores sociales y tradiciones culturales, y aliados del capitalismo y la modernidadrecordaban al de quienes cuestionaban la democracia y la corrección política y gloriaban la tradición, la autoridad, la disciplina, la caridad, la misericordia o la autarquía. Aunque otros sintieron melancolía por la revolución que pudo ser, Chirbes se convirtió en uno de los principales valedores por la persistencia con la que diseminó esas ideas en sus novelas, artículos y declaraciones públicas, que rayaron, aunque por razones muy distintas, con las de los nostálgicos del franquismo, sobre todo desde comienzos del siglo xxI. Las lecturas maximalistas y suspicaces de Chirbes admiten, desde luego, múltiples matices, ya que las decisiones políticas y las acciones humanas afortunadamente se rigen por más razones que las partidistas, pero son un punto de partida para la reflexión y superación de la presente coyuntura sanitaria. 
Además de estos aspectos ideológicos, esenciales en la obra de Chirbes, sus textos periodísticos avanzan su visión sociológica de la literatura; su concepción del 'realismo' como una indagación y explicación de realidades políticas, sociales, culturales y económicas, como una tradición literaria a la que conviene la experimentación y no exenta de exigencia y sutilezas estilísticas pese a que maneje discursos y 'materiales' cotidianos que no se consideran elevados ni nobles; su temprana querencia por autores a los que consideró maestros una vez reconocido como novelista, etc. Gracias a estos trabajos como periodista, Chirbes adquirió buena parte de la erudición geográfica, culinaria, arquitectónica e incluso artística de la que hizo gala; dio pistas de la sagacidad de sus observaciones y juicios, de su rigor estilístico, y de una veta satírica que se advierte en sus diarios y novelas, pero que en estas suele pasar más desapercibida por la dureza de lo relatado. Las reseñas que escribió para Ozono reflejan a su vez la importancia que Chirbes concedió a la crítica; por eso dio tanta trascendencia a las valoraciones de sus novelas, y por eso le desazonaron los reseñistas que escribieron a vuelapluma, sin fundamento o para encomiar artificiosamente y por encargo libros de dudosa enjundia. ${ }^{23}$

La labor periodística de Chirbes revela, pues, facetas muy importantes de su personalidad y obra que este artículo examina pero no agota, puesto que son muchos los textos y las cuestiones conceptuales, estructurales, estilísticas, que restan por analizar y que invito a seguir investigando. Este trabajo pretende constituir también una llamada de atención sobre la necesidad de seguir recuperando textos y documentos del pasado que se desconocen $\mathrm{u}$ omiten deliberadamente a la hora de ponderar la historia reciente de España, y más en un contexto tan regulador e intervencionista a consecuencia de la crisis sanitaria actual. La figura

23 En la Fundació Rafael Chirbes se conservan las reseñas de sus libros y correspondientes traducciones en cabeceras españolas, alemanas, francesas, italianas, inglesas..., que el escritor fue recopilando. 
de Rafael Chirbes y los textos de Ozono, una revista de difícil consulta para quienes no pudimos hacernos con un ejemplar en su momento, son una buena prueba de ello.

\section{Referencias bibliográficas}

Aniorte López, J. (2011) “Rafael Chirbes, traducción y reconocimiento en Alemania: los paisajes del alma", en Albadalejo Martínez J. M., Vega Cernuda, M. A. (eds.), Las letras valencianas en la literatura universal. Problemas de recepción y traducción: el paisaje y el tiempo, Sevilla, Bienza, 149-156.

Burgos-Segarra, G. (2021) “La gastronomía valenciana en la obra chirbesiana", en Lluch-Prats, J. (ed.), El universo de Rafael Chirbes, Barcelona, Anagrama, 245-265.

Calvo Carilla, J. L. (2013) “Lecturas críticas sobre la Transición: el caso de Rafael Chirbes", en Calvo Carilla, J., Peña Ardid C., Naval, M. A., Ara Torralba, J. C., Ansón Asadón, A. (coords.), El relato de la Transición. La Transición como relato. Zaragoza, Prensas de la Universidad de Zaragoza, 119-146.

Chirbes, R. (1975a) “Alejo Carpentier. El método de novelar (1)", Ozono. Revista de música y otras muchas cosas, 1, 70-71.

Chirbes, R. (1975b) "Cernuda. Entre la realidad y el deseo", Ozono. Revista de música y otras muchas cosas, 1, 79.

Chirbes, R. (1975c) “La hora de la verdad", Ozono. Revista de música y otras muchas cosas, 1, 68-69.

Chirbes, R. (1975d) “Tormento. Cine y literatura”, Ozono. Revista de música y otras muchas cosas, 1, 72-74.

Chirbes, R. (1975e) “El cine Español en la calle”, Ozono. Revista de música y otras muchas, 5, 48-51.

Chirbes, R. (1976) “Minicrisis editorial: Una lección de historia", Ozono. Revista de música y otras muchas cosas, 15, 31.

Chirbes, R. (1977a) “Historia de Elio: Autobiografía mística de don Ramón Tamames", Ozono. Revista de música y otras muchas cosas , 16, 65.

Chirbes, R. (1977b) “Luis Goytisolo: La constancia de escribir", Ozono. Revista de música y otras muchas cosas, 16, 59-61. 
Chirbes, R. (1977c) “Literatura: Sigue el vacío", Ozono. Revista de música y otras muchas cosas, 16, 13.

Chirbes, R. (1977d) “Literatura castellana. MERINO, José M.: Novela de Andrés Choz. Ed. Novelas y Cuentos. Madrid, 1976, 216 páginas, 125 ptas.", Ozono. Revista de música y otras muchas cosas, 18, 78 .

Chirbes, R. (1977e) “Tomar una papeleta al azar con amargura", Ozono. Revista de música y otras muchas cosas, 21, 40-41.

Chirbes, R. (1977f) "'Camada negra'. Por fin, un cine digno”, Chirbes, R. (1977) "Literatura: Sigue el vacío", Ozono. Revista de música y otras muchas cosas, 23, 47-48.

Chirbes, R (1977g) “Guía de libros. Narrativa castellana. Juan BENET: En el estado. Madrid. Ed. Alfaguara. 1977. 211 págs. 350 ptas.", Ozono. Revista de música y otras muchas cosas, 25, 78.

Chirbes, R. (1977h) “'El País'. La discreta tendenciosidad del centro", Ozono. Revista de música y otras muchas cosas, 26, 36-37.

Chirbes, R. (1977i) “Guía de libros. Narrativa. Mario Vargas Llosa: La tía Julia y el escribidor, Barcelona, Ed. Seix Barral. 1977. 447 pág. 400 ptas." Ozono. Revista de música y otras muchas cosas, 26, 79.

Chirbes, R. (1978) “'El tambor de hojalata' (1). El peligro de una conciencia sin historia", Ozono. Revista de música y otras muchas cosas, 34, 60.

Chirbes, R. (1979) “El último Delibes (.) El cansancio de la novela política", Ozono. Revista de música y otras muchas cosas, 41, 47-49.

Chirbes, R. (1984) “De Mariola al mar", Sobremesa, 4, 6-14.

Chirbes, R. (1985) “Las trufas. En busca del diamante negro", Sobremesa, 13, 16-25.

Chirbes, R. (1987a) “Ostras en el Atlántico francés. El jardín sumergido", Sobremesa, 33, 18-31.

Chirbes, R. (1987b) "Arzak. Senderos de gloria", Sobremesa, 34, 32-38.

Chirbes, R. (1987c) "Borghese al Tíber. Corazón de Roma", Sobremesa, 42, 58-68. 
Chirbes, R. (1988) “Champagne. El lujo como equilibrio”, Sobremesa, 54, 56-68. Chirbes, R. (1989) “Laponia. Teoría de la relatividad", Sobremesa, 58, 48-62.

Chirbes, R. (1990a) “Bali. Sombras del paraíso", Sobremesa, 68, 48-66.

Chirbes, R. (1990b) “Paris. St. Germain. Los virus de la memoria", Sobremesa, 76, 19-32.

Chirbes, R. (1992) “Carmen Martín Gaite. Un hermoso cuento", Sobremesa, 98, 12-14.

Chirbes, R. (1997) Mediterráneos, Madrid, Debate.

Chirbes, R. (2002) El novelista perplejo, Barcelona, Anagrama.

Chirbes, R. (2004) El viajero sedentario, Barcelona, Anagrama.

Chirbes, R. (2008) "Pucheros, ollas, olletes y cocidos", Anuario de la Cocina de la Comunitat Valenciana 2009, 206-208.

Chirbes, R. (2010a) Por cuenta propia. Leer y escribir, Barcelona, Anagrama.

Chirbes, R. (2010b) "Zapatero a la mesa de los caníbales", sin permiso. república y socialismo también para el siglo XXI [https:// www.sinpermiso.info/textos/zapatero-a-la-mesa-con-los-canbales], última consulta el 27/08/2020.

Chirbes, R. (2013) “Un escritor egoísta”, en Chirbes, R., Pecados originales. "La buena letra" \& "Los disparos del cazador", Barcelona, Anagrama, 7-10.

Chirbes, R. (2016) En la orilla, Barcelona Anagrama [1. a ed. 2013].

Chirbes, R. (2021) Diarios. A ratos perdidos 1 y 2, Barcelona, Anagrama.

Chirbes, R (inéd.) A ratos perdidos 4. TEMPUS FUGIT. ${ }^{24}$

Chirbes, $\mathrm{R}$ (inéd.) A ratos perdidos [5]. ${ }^{25}$

24 Comienza en mayo de 2006 ("Sigue mayo de 2006") y se abre con una cita de La creación del mundo, de Miguel Torga: “... tenía plena [...] penalidades". Concluye el 6 de enero de 2007.

25 En la parte superior derecha de la cubierta se escribe: "Esta vale". La primera entrada es del "8 de enero de 2007"; la última del "27 de agosto de 2008". 
Chirbes, R. (inéd.) A RATOS PERDIDOS [6]. ${ }^{26}$

Fernández Martínez, D. (2021) “Et in Arcadia Ego. El viaje a Creta de Rafael Chirbes", en Lluch-Prats, J. (ed.), El universo de Rafael Chirbes, Barcelona, Anagrama, 293-306.

García Montero, L. (2013) “En la orilla”, en El País, "Páginas en presente" [https://elpais.com/cultura/2013/12/19/actualidad/1387467794_395351.html], última consulta el 26/08/2020.

García Prats, S. (2013) Memoria y ciudad en "Mediterráneos" (1997). Implicaciones simbólicas, topográficas y antropológicas de la escritura de viajes. Dissertation zur Erlangung des Doktorgrades der Philosophischen Fakultät der Christian- Albretchs. Universität zu Kiel.

Herralde, J. (2006) "Rafael Chirbes: la voz de la verdad", en Herralde, J., Por orden alfabético. Escritores, editores, amigos, Barcelona, Anagrama, 77-85.

Llamas Martínez, J. (2017) “Una aproximación al ritmo lingüístico, el tono y la puntuación en las novelas de Rafael Chirbes", Tonos Digital, 32, s. p. [1-28].

Llamas Martínez, J. (2020) "La biblioteca de la Fundación Rafael Chirbes: Anotaciones y marcas de lectura", Anales de Literatura Española, 33, 125-140.

Martínez Rubio, J. (2016) “Retratos del tiempo con pirámides al fondo. La visita de Rafael Chirbes a Egipto", en Rodrigo Mora, M. J., Pano Alamán A., Betti, S. (eds.), Tempus en Misr. Historia y porvenir del Hispanismo en Egipto, Bolonia, Emil, 155-168.

Moreno-Caballud, L. (2012) "La imaginación sostenible: culturas y crisis económica en la España actual”, Hispanic Review 80, 535-555.

Serber, D. C. (2019) “Mimoun de Rafael Chirbes: Ecos y espejos de la España de la Transición", en Iglesias, C., Orsini-Saillet, C. (dirs.), Hispanística XX: Regards sur le paysage. Monde hispanique contemporain, Binges, Orbis Tertius, 183-199.

26 En la parte superior derecha de la cubierta se indica: "Este sí". La primera entrada es del "30 de agosto de 2008"; la última del "9 de agosto de 2015". Otra de las versiones del diario concluye en junio. 
VAL, F. del (2014-2015) "Biocronología de Rafael Chirbes", Turia: revista cultural, 112, 280-305.

Vázquez Montalbán, M. (1985) El pianista, Barcelona, Seix Barral.

Veiga, M. (2011) "Deciphering the Past, Interpreting the Present: Self and Identity in Mediterráneos by Rafael Chirbes", en Crowley, P., Humble, N., Ross, S. (eds.), Mediterranean Travels. Writing Self and Other from the Ancient World to Contemporary Society, Routledge, New York, 197-208. 
